\title{
O princípio do fim: o "torna-viagem", a imigração e a saúde pública no Porto do Rio de Janeiro em tempos de cólera
}

\author{
The beginning of the end: \\ the return-trip, immigration and public health \\ at Rio de Janeiro's Port in times of cholera
}

Fernanda Rebelo, Marcos Chor Maio e Gilberto Hochman

\section{Introdução}

No último quartel do século XIX, o fluxo migratório intensificou-se, atingindo o seu pico nas primeiras décadas do século XX. Entre 1881 e 1915, cer-

Fernanda Rebelo é doutora pelo Programa de Pós-Graduação em História das Ciências da Saúde da Casa de Oswaldo Cruz, Fundação Oswaldo Cruz (COC/Fiocvruz) e pós-doutoranda em História da Ciência na Universidade Federal de Santa Catarina, Florianópolis, Brasil (feferebelo@yahoo.com.br).

Marcos Chor Maio é professor e pesquisador da COC/Fiocruz, Rio de Janeiro, Brasil (maio@fiocruz.br).

Gilberto Hochman é professor e pesquisador da COC/Fiocruz, Rio de Janeiro, Brasil (hochman@coc. fiocruz.br).

Artigo recebido em 30 de dezembro de 2010 e aprovado para publicação em 24 de fevereiro de 2011. 
ca de 31 milhões de europeus imigraram para as Américas. A substituição das embarcações à vela pelos navios a vapor, a instalação de cabos telegráficos e de ferrovias propiciaram meios de comunicação e de transporte mais rápidos e baratos. A partir de então, a imigração enquadra-se num movimento geral de circulação de mercadorias, mão de obra e capital. (Klein, 2000: 23-25; Costa Leite, 2000: 184-186).

Os vapores, que possibilitaram a realização de viagens mais rápidas, facilitaram também a circulação mais intensa de microorganismos entre populações. Epidemias e pandemias tornaram-se mais frequentes e o controle dos micróbios inseparável da vigilância dos indivíduos. As doenças ameaçavam o desenvolvimento da economia capitalista, pois castigavam a mão de obra e prejudicavam o livre comércio, com a imposição de medidas profiláticas como as quarentenas e as desinfecções de navios, bagagens, mercadorias e passageiros nos portos de escala e no desembarque (Cueto, 2007: 27-34; Löwy, 2006:15-19).

A estrutura montada para a recepção e inspeção de imigrantes no Rio de Janeiro - a Hospedaria da Ilha das Flores, o Lazareto da Ilha Grande e o Hospital de Isolamento da Jurujuba - não tinha capacidade suficiente para acolher os enfermos e possíveis portadores saudáveis da moléstia, que deveriam permanecer em quarentena. Assim, as autoridades sanitárias exigiam que os navios retornassem a seus portos de origem, realizando o "torna-viagem". Era o fim do sonho imigratório para milhares de indivíduos e famílias.

Neste trabalho, será reconstruído o sistema de recepção e inspeção de imigrantes, realizado pela Inspetoria Geral de Saúde dos Portos no final do século XIX, por meio de quatro navios que chegaram ao porto do Rio de Janeiro, no ano de 1893 , com surto de cólera a bordo. ${ }^{1}$ Partimos do pressuposto de que a recepção e o controle de mercadorias e passageiros guardam relação intrínseca com a institucionalização dos serviços sanitários no país, pois a necessidade de atender às normas da profilaxia portuária internacional e de proteger a cidade de epidemias que poderiam chegar a bordo dos navios exigiu a intervenção do Estado. Foi necessário criar instituições para organizar a população imigrante e as questões sanitárias advindas dela, não só no Rio de Janeiro, a capital federal, mas também nos portos dos outros estados da federação que recebiam os trabalhadores estrangeiros. Dessa forma, a necessidade de controlar a imigração nos portos contribuiu para o processo de formação e ampliação da autoridade de saúde pública pelo território nacional na Primeira República. ${ }^{2}$

Estudos têm analisado o efeito de epidemias em centros urbanos. ${ }^{3}$ Neste artigo, abordamos os percursos das moléstias - que passaram a se propagar rapidamente entre portos, junto ao grande fluxo de pessoas e mercadorias - antes de elas se instalarem nas sociedades. Nosso objetivo é analisar as epidemias ainda dentro dos navios, durante a viagem de imigração e o encontro da população es- 
trangeira com o serviço sanitário dos portos, entre o final do século XIX e o início do XX.

\section{O "torna-viagem"}

O Vapor Carlo R., de passageiros, cortando o oceano e perdendo sempre doentes de cólera morbus, faz lembrar alguma coisa horrorosamente fantástica, que o próprio Dante não descreveu nos seus círculos infernais: insensivelmente recorda a lenda de Ashaverus, deixando o horrível morbo após si em todos os lugares por onde passava (RMJNI, Relatório da Inspetoria Geral de Saúde dos Portos, 1894-1895: A-S-10 - Inspetor Dr. José de Souza da Silveira).

Entre os meses de agosto e setembro de 1893, quase seis mil pessoas tiveram seus destinos alterados. Ao se aproximarem do porto do Rio de Janeiro, quatro vapores italianos que carregavam cerca de 1.500 imigrantes, após um mês de viagem, tiveram que retornar para seus portos de embarque, abortando o sonho de indivíduos e famílias que deixavam suas pátrias em busca de melhores condições de vida.

A cólera, que em 1892 irrompera na França, já havia invadido vários países europeus, atravessado o Atlântico e adentrado os Estados Unidos. Os vapores, aglomerados de emigrantes, levavam consigo a doença pelos portos por onde passavam.

Em abril de 1893, representações diplomáticas brasileiras no exterior começaram a enviar avisos oficiais sobre a propagação da cólera ${ }^{4}$ por portos europeus. ${ }^{5}$ Os navios de imigrantes procedentes de tais localidades deveriam ser recebidos nos portos da República somente após passarem por "tratamento" sanitário: a desinfecção, com o uso de produtos químicos ou do vapor d'água, da embarcação, das bagagens, das roupas e dos objetos pessoais dos passageiros. A desinfecção era realizada no Lazareto da Ilha Grande - localizada no sul do Estado do Rio, no município de Angra dos Reis -, para onde os navios deveriam se dirigir, quando os serviços sanitários identificavam casos suspeitos ou confirmados de doentes (AN. Série Saúde, notação ISI-96 - MJNI, Serviço Sanitário, abril de 1893).

Com o recrudescimento da epidemia, o governo brasileiro suspendeu a corrente imigratória, recusando os imigrantes transportados em vapores saídos 
da Itália e da Espanha depois de 16 de agosto de 1893. Todos os portos franceses e africanos do Mediterrâneo foram declarados "infeccionados". Foi imposta a quarentena para "navios infectados ou suspeitos" de cólera e só no começo do ano de 1894 a situação se normalizou, sendo liberada a imigração de locais considerados livres da epidemia. ${ }^{6}$

Dentre as medidas profiláticas e defensivas, o "torna-viagem" - isto é, o retorno ao porto de origem - era utilizado em casos extremos, quando havia uma grande quantidade de doentes e mortos a bordo. Infelizmente foi este o caso dos quatro vapores com imigrantes que adentraram o porto do Rio de Janeiro entre os meses de agosto e setembro de 1893.

O paquete "Remo", que havia saído de Gênova no dia 15 de agosto, foi declarado "infeccioso" no dia 16, chegando ao porto de Nápoles no dia 17. Ele estava com excesso de passageiros - 1.494 pessoas apinhadas - e as condições sanitárias eram péssimas. Três passageiros haviam morrido e, ao chegar ao ancoradouro do Lazareto da Ilha Grande, outros três tinham contraído a moléstia. O "Remo" não foi admitido "à livre prática nos portos do Brasil". ${ }^{7}$ Proibido de entrar de entrar no país, foi obrigado a retornar ao seu porto de origem. Ao retornar viagem, mais de 60 pessoas foram atacadas pelo flagelo. Conforme informações do consulado brasileiro em Barcelona, acreditava-se que a cólera havia chegado à Espanha junto com o navio italiano quando este voltava do Brasil, pois a epidemia começara a grassar em Tenerife, nas Ilhas Canárias (RMJNI - Relatório da Inspetoria Geral de Saúde dos Portos, 1894-1895: A-S-9).

O vapor "Andréa Doria" chegou à Ilha Grande em 12 de setembro. Havia partido de Nápoles justamente na data de proibição da entrada de imigrantes no Brasil - 16 de agosto. Os passageiros se encontravam aglomerados e em péssimas condições de higiene e asseio, ten do ocorrido durante a viagem $91 \mathrm{ca}-$ sos fatais de cólera. Como existiam ainda muito doentes à sua chegada, foi ordenado o "torna-viagem" (RMJNI - Relatório da Inspetoria Geral de Saúde dos Portos, 1894-1895: A-S-9). Quatro dias depois foi a vez do vapor "Vincenzo Florio" aportar na Ilha Grande, em condições idênticas às do vapor "Remo". Mesmo após a sua chegada, as pessoas continuaram a adoecer, tendo de retornar a viagem (RMJNI - Relatório da Inspetoria Geral de Saúde dos Portos, 1894-1895: A-S-9).

O vapor "Carlo R.” partiu de Gênova em 27 de julho. Em Nápoles recebeu 1.300 emigrantes, seguindo viagem no dia 29 em direção ao Rio de Janeiro. $\mathrm{O}$ primeiro óbito ocorreu no dia 31. "O comandante, ao invés de retroceder viagem para o lazareto de Nápoles, onde os doentes poderiam ter recebido tratamento, continuou a viagem, informando às autoridades que os casos não eram de cólera, mas de gastroenterite". No decorrer da viagem, que durou mais de 20 dias, outros passageiros faleceram. Como o vapor era pequeno, não havia local para iso- 
lar os doentes. Ao chegar ao Lazareto da Ilha Grande, no dia 24 de agosto, havia mais de 100 mortos a bordo, e era possível que tivesse ainda um número considerável de doentes e mortos, pois o vapor "exalava um cheiro fétido" ((RMJNI Relatório da Inspetoria Geral de Saúde dos Portos, 1894-1895: 10-11; RMJNI, 1893 e 1894: 280).

A viagem transoceânica, realizada pelos imigrantes dentro dos vapores, era cheia de situações de risco - a aglomeração de pessoas, a insalubridade dos navios e a má alimentação - que, frequentemente, provocavam alguma enfermidade. Este adoecer possuía certas especificidades e carregava em si uma série de consequências que poderia transformar os destinos daquelas pessoas de forma individual e coletiva. A primeira delas era a possibilidade de uma epidemia a bordo, fato que, naquele período e naquelas circunstâncias, tornava-se quase impossível de ser controlada.

O medo generalizado do contágio de doenças levou os médicos a desempenharem um papel preeminente nos portos onde os imigrantes chegavam. Ainda que no século XIX não se conhecesse a etiologia das principais doenças que afetavam as populações, sabia-se que algumas eram transmissíveis, ligadas a aglomerações de pessoas em um mesmo local e a "maus hábitos higiênicos". Compreendia-se ainda que em alguns lugares certas doenças eram prevalentes, como a peste bubônica na Ásia e a febre amarela no Caribe, e que poderiam tomar forma de epidemias a partir da comunicação entre populações (Weindling, 1995: $1-16)$.

A circulação de infecções entre continentes, proporcionada pelo grande fluxo de pessoas e mercadorias, demandava a intervenção do Estado. Foi necessário criar instituições para gerenciar, recepcionar e inspecionar passageiros, em especial os que viajavam na $3^{\mathrm{a}}$ classe dos vapores, em sua maioria imigrantes. ${ }^{8}$

\section{As instituiçães de recepção e inspeção}

O Brasil, como um dos grandes países imigrantistas, possuía duas instituições de recepção e inspeção de trabalhadores estrangeiros, ambas situadas no estado do Rio de Janeiro: a Hospedaria de Imigrantes da Ilha das Flores, localizada no bairro de Neves, em São Gonçalo; e o já mencionado Lazareto da Ilha Grande.

Quando não havia epidemia nos portos de embarque e nem naqueles que o navio tocava para fazer operações de carga e descarga durante a viagem, os imigrantes eram encaminhados para a hospedaria, onde permaneciam por cerca de uma semana, até serem conduzidos para uma fazenda ou colônia, no interior do país. Caso o navio tivesse partido ou ancorado em "porto infeccionado", ou 
apresentasse moléstia a bordo no momento da chegada, deveria ser encaminhado para o lazareto para cumprir quarentena de acordo com o período de incubação da doença. ${ }^{9}$

Os quatro vapores chegaram com surto de cólera quando ocorria uma grande epidemia dessa moléstia na Europa. De acordo com os procedimentos de profilaxia adotados pelo Serviço Sanitário do Porto do Rio de Janeiro na época, os passageiros não desembarcaram, seguindo diretamente para o ancoradouro do Lazareto da Ilha Grande.

Apesar de terem sido encaminhadas para o lazareto, as embarcações não permaneceram em quarentena, pois logo foram proibidas de atracar, tendo que retornar para a Itália. O tratamento disponível para combater a cólera nos navios era a desinfecção da embarcação, das roupas e dos objetos pessoais dos passageiros. Os mortos eram jogados ao mar, os doentes recebiam uma hidratação, o restante dos passageiros tinha seus pertences "fumigados" pelas estufas de desinfecção e permanecia em quarentena. ${ }^{10}$

Os quatro navios, proibidos de atracar, nem sequer passaram pelos procedimentos de rotina - desinfecção e quarentena no lazareto. Logo voltaram ao mar e os passageiros viveram o terror de permanecer por mais um mês dentro de um navio com uma epidemia de cólera. Durante a viagem de volta, ocorreram muitas mortes.

Parecerá, à primeira vista, a quem não observar com acurada atenção e necessário critério, que as medidas de extremo rigor tomadas pelo governo e autoridades sanitárias, em relação aos vapores supramencionados, foram atos de desumanidade, de verdadeiro vandalismo, contrários aos princípios de fraternidade e atentatórios dos direitos das gentes; mas quem tiver uma vez visitado um desses paquetes com imigrantes, sobretudo os italianos, perfeitos necrotérios ambulantes [grifos do autor] em épocas epidêmicas, concordará que outro não podia ser o proceder das autoridades incumbidas de velar a saúde pública (RMJNI - Relatório da Inspetoria Geral de Saúde dos Portos, 18941895: A-S-9 - Inspetor Dr. José de Souza da Silveira).

A ordem para que "os necrotérios ambulantes" - palavras usadas pelo inspetor de Saúde dos Portos, dr. José da Silveira, para se referir aos navios - voltassem para seus portos de origem, gerou mal-estar entre as autoridades de saúde pública e na população carioca. $\mathrm{O}$ caso dos vapores, que teve repercussão nos principais jornais da capital, ${ }^{11}$ foi visto como um ato desumano dos governantes. No entanto, segundo o dr. Silveira, foi um mal necessário para impedir o pior: o 
alastramento da cólera, começando pelo Rio de Janeiro e adentrando o interior do país, junto à marcha dos imigrantes. ${ }^{12} \mathrm{O}$ mesmo dr. Silveira lembra que as autoridades brasileiras tinham que lidar com um problema prático: o Lazareto da Ilha Grande e o Hospital Marítimo da Jurujuba não tinham capacidade física para receber quase seis mil pessoas num curto espaço de tempo.

O fato teve também repercussão internacional e gerou desavenças diplomáticas. A Itália, o maior exportador de mão de obra para o Brasil, fez questão de recordar tal evento, quando, um ano depois, em 1894, discutia-se a legislação sanitária para a imigração, durante uma convenção. ${ }^{13}$

Os sintomas da cólera - diarréia volumosa, vômitos, cólicas abdominais e espasmos musculares violentos - causavam verdadeiro pânico (Lewinsohn, 2003: 109-110). Dentro dos navios, a situação poderia se tornar mais degradante e dolorosa para todos, mas principalmente para familiares, pois obrigatoriamente era necessário jogar o corpo ao mar para impedir o contágio. ${ }^{14}$

Segundo Rosenberg (1992:110), as epidemias proporcionaram respostas de vários aspectos em muitos setores da sociedade. Um estudo dessas respostas pode gerar material para a construção de valores culturais e práticas numa determinada época, relacionados à ciência, religião, ao tradicionalismo e às inovações. Neste trabalho, utilizou-se o momento de uma pandemia de cólera para analisar as questões sanitárias relacionadas ao fluxo imigratório. Existe uma relação intrínseca entre o serviço sanitário dos portos e a construção e a ampliação do aparato de saúde pública pelo território nacional. Estudos - como o de Birn (1997), no caso do Public Health Service, nos Estados Unidos, e o de Maglen (2002), sobre o Port Sanitary Authority, na Inglaterra - têm demonstrado a relação entre a necessidade de controle de mercadorias e passageiros com a construção deste aparato.

No Brasil, Castro Santos (2004: 251-256) observou que, mesmo intermitentes e irregulares, os serviços sanitários dos portos antecederam a institucionalização do processo da reforma sanitária no país. Autoridades de saúde compreendiam que o porto, sendo a ligação da cidade com o exterior, constituía um local propício para o início e o alastramento de uma epidemia.

A preocupação com o saneamento deste espaço se estabelece como uma questão de importância na atuação governamental. Mesmo em período de descentralização das políticas de saúde, o porto foi sempre uma questão da alçada do governo federal, ${ }^{15}$ pois, a partir da primeira metade do século XIX, os países que quisessem continuar a participar das trocas comerciais teriam que atender a normas da profilaxia marítima internacional, homogeneizando suas práticas sanitárias. Para que isso ocorresse, foi necessário organizar o espaço portuário. ${ }^{16}$

O controle da corrente imigratória era realizado por oficiais e médicos da Inspetoria Geral de Saúde dos Portos (IGSP), que realizavam a primeira ins- 
peção no momento em que o navio atracava. Depois, os estrangeiros eram encaminhados para a Hospedaria de Imigrantes, sob a responsabilidade da Inspetoria Geral de Terras e Colonização. Contudo, se houvesse doentes a bordo, o vapor deveria ancorar no lazareto.

\section{O Lazareto da Ilha Grande}

O Lazareto da Ilha Grande - instituição ligada à Inspetoria Geral de Saúde dos Portos, órgão subordinado ao Ministério da Justiça e Negócios Interiores (MJNI) - começou a ser construído em 1884, com a função de controlar a propagação de epidemias que poderiam chegar através dos navios estrangeiros. Nesse mesmo ano, a cólera estava se espalhando pela Europa e chegara à Argentina, alcançando o Brasil nos primeiros anos da década de 1890 (RMJNI - Relatório da Inspetoria Geral de Saúde dos Portos, 1894-1895: A-S-9 - Inspetor Dr. José de Souza da Silveira).

A quinta pandemia de cólera do século XIX (1881-1896) atingiu o Brasil no auge dos fluxos comerciais e migratórios com a Europa, a América e o Oriente (Benchimol, 1999: 251). Com a finalidade de transcorrer de acordo com as regras internacionais de comércio, segurança e profilaxia de doenças, aprovadas através de convenções internacionais na Europa e com os nossos vizinhos do Rio da Prata, o ministro do Império, o barão de Mamoré, ordenou que se construísse o lazareto (RMJNI - Relatório da Inspetoria Geral de Saúde dos Portos, 1894-1895: A-S-9 - Inspetor Dr. José de Souza da Silveira).

No lazareto, o tratamento das doenças transmissíveis era feito com o isolamento dos enfermos e a quarentena dos passageiros saudáveis que, por terem estado no "meio infeccionado", tinham sido expostos ao contágio da moléstia e poderiam adoecer de um momento para o outro. No local, eram realizados também os processos de desinfecção das embarcações, das roupas e bagagens dos passageiros e da tripulação (Silvado, 1903: 317). ${ }^{17}$

De acordo com a profilaxia internacional, firmada mediante convenções sanitárias, as doenças consideradas transmissíveis e sujeitas à regulamentação preventiva nos portos eram a cólera, a peste bubônica e a febre amarela. Essas moléstias eram as mais temidas e comuns durante a viagem dos imigrantes. As condições nos navios eram propícias às epidemias de cólera e de peste a bordo, ao passo que a febre amarela, endêmica em algumas localidades da América do Sul e do Caribe, ocorria nos portos de escala ou na chegada do imigrante ao porto de destino (RMJNI, 1893: 346). ${ }^{18}$

Quando o Brasil ainda não possuía lazareto, montava-se um "acampamento sanitário" em algum ponto do litoral que fosse arejado, suficientemente 
alto e ensolarado para realizar a evacuação do navio e a dispersão de sua tripulação. Antes da construção do lazareto, os portos brasileiros eram fechados como medida de prevenção contra epidemias. Houve ocasiões de se "repelir à bala navios que tentaram forçar a entrada no porto, a despeito dos sinais da fortaleza" (Fornal do Commercio, 29 de agosto de 1893).

O fechamento dos portos, quando ocorriam epidemias, causava sérios prejuízos ao comércio internacional. Quando isso acontecia, chegavam reclamações por telegramas de todos os países. Um fato em especial, que teve grande repercussão na imprensa, foi quando o presidente da Academia de Ciência da França reclamou diretamente com um ministro brasileiro sobre as medidas de fechamento dos portos, considerando-as excessivas. No entanto, segundo informou o fornal do Commercio, na mesma edição de 29 de agosto de 1893, "o governo manteve-se inabalado, respondendo aos sábios franceses com disposições do seu próprio regulamento sanitário".

Em períodos sem epidemias na cidade, quando os vapores atracavam no porto, os imigrantes eram recebidos por intérpretes uniformizados, de modo a serem reconhecidos como agentes do governo brasileiro pelos passageiros. Os comandantes entregavam nas mãos dos intérpretes uma lista constando nome, idade, sexo, nacionalidade e profissão de todos os passageiros (RMIVOP, 1908: $62,83)$.

\section{A Hospedaria da Ilha das Flores}

A Hospedaria de Imigrantes - sob o controle da Inspetoria de Terras e Colonização, agência subordinada ao Ministério da Agricultura - foi instalada em 1883. Os imigrantes que chegavam saudáveis, sem sintomas de enfermidade transmissível aparente, eram direcionados para a hospedaria, onde permaneciam por uma semana até serem encaminhados para uma fazenda ou colônia.

A chegada de grande quantidade de estrangeiros, em tempos de epidemia, constituía um problema para as autoridades de saúde pública e despertava medos na população, explicitados através da imprensa:

A Ilha das Flores é um foco de moléstias perigosas:

o desleixo da saúde pública

Há pouco tempo, [quando] mostramos o descuido lamentável da Saúde Pública, referente ao desembarque de emigrantes na Ilha das Flores, deu-se um grito de alarme ante a ameaça que pousava so- 
bre a população carioca (...). O que há realmente de verdadeiro é o seguinte: os emigrantes, portadores de terríveis moléstias, têm desembarcado livres pelo simples fato (certamente importante para os senhores encarregados de zelar pela saúde da cidade) de virem para o Brasil... Isto é, positivamente, irrisório. Os médicos da saúde pública, nem sempre, com raras exceções, dão-se ao trabalho de um exame minucioso nos navios que aportam à Baía da Guanabara, trazendo nos seus bojos imundos estrangeiros que vêm procurar ocupação nos núcleos agrícolas... (Vanguarda, 27 de abril de 1926/DAD - COC/FIOCRUZ).

Imagem 1 - Mapa indicando as instituições de recepção e inspeção da corrente imigratória:

Porto do Rio de Janeiro, Hospedaria de Imigrantes da Ilha das Flores, Hospital da Jurujuba e Lazareto da Ilha Grande.

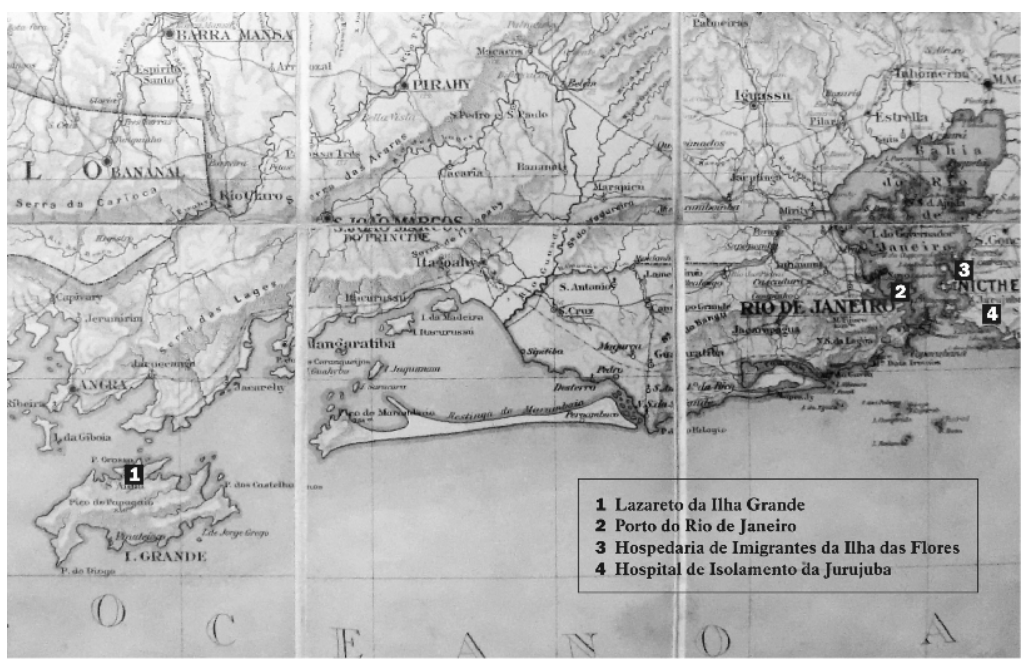

Fonte: Rio de faneiro: ferrovias e porto, Laemmert, 1892 - Acervo Cartográfico da Biblioteca Nacional/RJ.

A Ilha das Flores era vista como um foco de contágio de doenças, principalmente a varíola, o tifo e a disenteria. Esta última visitava com bastante frequência não só a hospedaria, mas também os vapores. Além de ser considerada como foco das doenças "exóticas" trazidas pelos imigrantes, a hospedaria também era entendida como um local de propagação da febre amarela, doença endêmica no Rio de Janeiro e para a qual se dizia que o imigrante não possuía imunidade (O Globo, 14 de abril de 1926/DAD - COC/FIOCRUZ). 


\section{O sistema de recepção e inspeção adotado pela Inspetoria Geral de Saúde dos Portos}

A recepção e a inspeção de passageiros imigrantes eram realizadas no final do século XIX com uma mistura de entendimentos sobre germes e miasmas, percepções que poderiam ir desde as relações das moléstias com a sujeira dos navios e com o asseio pessoal, até as questões ligadas à moralidade e ao comportamento do indivíduo (Fairchild, 2000: 42-43).

Com a difusão da microbiologia ${ }^{19}$ no Brasil, a forma de combate às epidemias não se sustentava mais pelo ideário dos miasmas, as matérias em putrefação, de origem vegetal e animal, que constituíam a causa mais direta das epidemias. No entanto, permanecia a noção do meio ambiente, que contribuía para a disseminação dos micróbios, como fator determinante para a propagação de doenças (Benchimol, 1999: 191-200).

As práticas sanitárias no final do século XIX e início do XX sugerem múltiplas articulações entre explicações "infeccionistas", que relacionavam as doenças ao meio ambiente (miasmas), e "contagionistas", que acreditavam no contágio direto entre indivíduos. $\mathrm{O}$ higienismo mesclava-se à teoria pasteuriana, gerando a permanência da prática da desinfecção e do controle da insalubridade nos centros urbanos (Caponi, 2002: 592-594). ${ }^{20}$

Desde a época colonial, já existia no território brasileiro uma preocupação com a defesa sanitária contra a invasão de doenças. Com a abertura dos portos, em 1808, houve a necessidade de se construir um local para o isolamento dos doentes que chegavam pelo mar. A ilha de Villegaignon, na baía da Guanabara, funcionou como uma espécie de lazareto, conhecido como o "Degredo das Bexigas", por abrigar doentes de varíola, moléstia que era frequentemente associada ao escravo africano (Sardinha, 1916: 3).

Em 1843 foi baixado o Decreto ${ }^{\circ} 268$ para o porto do Rio de Janeiro, que instituía quarentenas e inspeção de navios, a cargo do Ministério do Império. Nessa época, a cidade ainda estava livre da febre amarela, da peste e da cólera. O Hospital de Jurujuba, que tratava os marinheiros enfermos, existia desde 1851, ano da primeira epidemia de febre amarela no Rio de Janeiro. Depois passou a funcionar como hospital marítimo de isolamento, não só para marinheiros enfermos, mas também para atender passageiros e tripulações de navios que pudessem chegar com doenças contagiosas (Sardinha, 1916: 7-15).

Os serviços sanitários marítimos no Brasil só começaram a funcionar de forma um pouco mais organizada no final do século XIX, em virtude da pandemia da cólera na Europa, que alcançou Buenos Aires em 1884. Sabia-se que, mais dia menos dia, ela alcançaria o território nacional. A principal preocupação era a de não deixar que as doenças chegassem ao Rio de Janeiro, ca- 
pital federal e um dos principais portos marítimos e comerciais da América do Sul. ${ }^{21}$

A polícia sanitária marítima brasileira do final do século XIX baseava-se no isolamento - chamado de "sequestro" ou quarentena de navios e passageiros - na desinfecção e nas visitas sanitárias. No porto, havia equipes médicas encarregadas de realizar as visitas sanitárias aos navios. Uma parte delas ficava responsável pelas visitas internas aos navios que já se achavam fundeados. A outra inspecionava todos os navios que chegavam de portos estrangeiros. Essas visitas tinham por fim verificar o estado de saúde a bordo e impor as quarentenas.

Nas visitas externas, logo que qualquer navio adentrava o ancoradouro, um médico dirigia-se para o local e, antes de subir a bordo, procedia a um interrogatório junto ao comandante da embarcação. Dependendo do estado do navio, o médico entrava a bordo e verificava a veracidade das informações do comandante, a quem concedia ou não a já mencionada "livre prática". Mas, se por acaso, mesmo antes de penetrar a bordo, o delegado sanitário encontrasse razões que lhe fizessem acreditar que o navio estava infeccionado, com doentes a bordo, este deveria se dirigir ao ancoradouro do Lazareto da Ilha Grande para lá sofrer as inspeções médicas.

O lazareto e seus sistemas quarentenários, auxiliados ou não pela desinfecção, eram a principal arma com que se protegia a salubridade pública no Brasil. Nessa instituição passava-se todo o enredo do qual a visita sanitária no porto consistia apenas uma fração. O navio poderia permanecer no lazareto em duas espécies de quarentena, a de "rigor" e a "de observação". Em ambas, dava-se o isolamento do navio. No caso da "quarentena de observação", o navio deveria permanecer até expirar o prazo máximo de incubação da moléstia, que começava a ser contado a partir da data de entrada do navio ou passageiro no lazareto e não ocorria o processo de desinfecção. Na "quarentena de rigor", após o desembarque dos passageiros no lazareto, procedia-se ao desembarque das cargas e à desinfecção do navio e dos objetos suspeitos de transmitir a moléstia.

Com relação aos passageiros, estes iam para o Lazareto da Ilha Grande, para lazaretos flutuantes ou para o hospital de isolamento de moléstias contagiosas, em Jurujuba. Havia ainda hospitais flutuantes, que poderiam ser montados dentro de embarcações, caso os estabelecimentos em terra não dessem conta da quantidade de doentes em épocas de epidemia. ${ }^{22}$

Ficavam também sob a responsabilidade da Inspetoria Geral de Saúde do Porto do Rio de Janeiro os serviços sanitários dos portos nos estados. A partir do Regulamento Portuário de 1893 (Decreto n.1558, de 7 de outubro de 1893), foi estabelecido um novo serviço de profilaxia para a defesa sanitária (Sardinha, 1916: 14). 
No lazareto, a desinfecção era feita em câmaras de enxofre. As estufas eram previamente aquecidas e os objetos colocados dentro delas para receberem tratamento por cerca de 20 minutos sob a influência do vapor úmido, gastando de dez a 15 minutos para secarem (Sodré, 1895: 226). ${ }^{23}$ As autoridades procuravam prevenir os passageiros de não levarem em suas malas objetos de valor nem outros capazes de se deteriorarem no processo de desinfecção, como plumas, pelicas, objetos de couro, metal etc. Danos às bagagens eram frequentes e objetos como selins, sapatos, chapéus costumavam sair "torrados" das estufas (Sodré, 1895: 226).

Imagem 2 - Charge mostrando o antes e o depois da passagem pelo processo de desinfecção

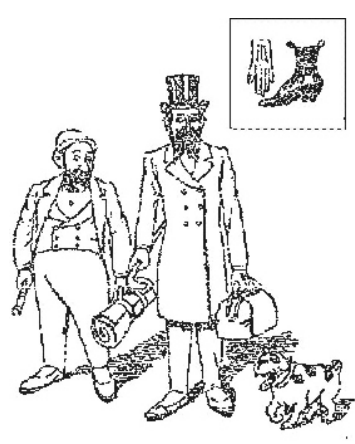

Aniea da degiglecrĩno.

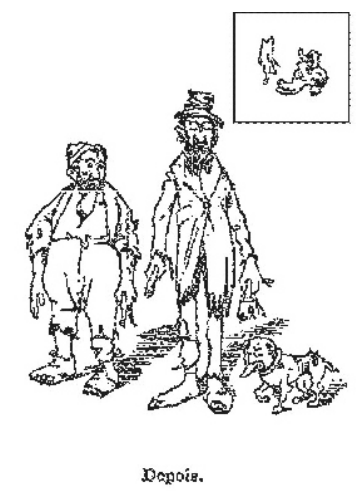

Fonte: Gazeta de Notícias, 6 de janeiro de 1895, p.1.

O foco da desinfecção eram sempre os passageiros de $3^{\mathrm{a}}$ classe, imigrantes em sua maioria. Os passageiros tinham que pisar em tapetes molhados com uma solução desinfetante de cloreto de mercúrio. Depois eram encaminhados para o lavatório, levando sabonete, escova de unha e balde para as águas servidas. Suas vestes e sapatos eram esfregados com germicidas. Passageiros de $3^{\mathrm{a}}$ ou de $2^{\mathrm{a}}$ classe considerados suspeitos pela falta de asseio, eram despidos e submetidos à desinfecção mais rigorosa. A assepsia terminava após a pulverização dos passageiros com ácido fênico. Após passarem por todo o processo, recebiam uma carteira de saúde na qual se comprovava a desinfecção (Benchimol, 1999: 261).

Era este o enredo da recepção e da inspeção de imigrantes no porto do Rio de Janeiro no final do século XIX e nas primeiras décadas do XX. Abordamos aqui o reverso da imigração, o "torna-viagem”, ou seja, a proibição da entrada de imigrantes doentes no Brasil pela autoridades sanitárias em período de pandemia. 


\section{Considerações finais}

Este artigo abordou a chegada de imigrantes ao porto do Rio de Janeiro em períodos epidêmico no final do século XIX e no início do século XX. A estrutura montada para a recepção e inspeção destes passageiros, como a Hospedaria da Ilha das Flores e o Lazareto da Ilha Grande, não tinha a capacidade de receber e dar assistência à quantidade de doentes e possíveis portadores da moléstia incubada, que deveriam permanecer isolados em observação. Dessa forma, só restava aos navios realizarem o "torna-viagem", o retorno ao porto de origem.

Durante o "torna-viagem", os imigrantes vivenciavam o drama de ter que permanecer por mais um mês dentro de um navio com surto epidêmico. $\mathrm{O}$ navio era o palco onde se passava a tragédia da experiência com a doença e com a possibilidade de sua própria morte, bem como a de seus amigos e parentes. O retorno representava também o fracasso do sonho imigratório. Era o princípio do fim de uma jornada planejada, da esperança por tempos melhores, daqueles que um dia abandonaram suas terras em busca de um futuro almejado em um "Novo Mundo". O "torna-viagem" constitui a experiência histórica do fracasso do sonho imigratório, compartilhado por milhares de indivíduos.

Nosso objetivo, neste artigo, foi analisar as epidemias ainda dentro dos navios, durante a viagem de imigração e o encontro da população estrangeira com o serviço sanitário dos portos, entre o final do século XIX e o início do XX.

Notas

1. A cólera, com seus sintomas assustadores - diarréia volumosa, vômitos, cólicas abdominais e espasmos musculares violentos - causava pânico às pessoas, em especial dentro dos navios. O rosto do paciente fica azulado, a pele murcha, mãos e pés ficam gelados, escurecidos, contraídos e enrugados. A morte ocorre em um curto espaço de tempo, às vezes em poucas horas após o aparecimento dos sintomas (Lewinsohn, 2003:109110).
2. Hochman (1998: 25-28) mostrou que o problema do combate às epidemias na Primeira República exigiu a implementação de políticas de saúde pública, que desempenharam papel importante na criação e no aumento da capacidade do Estado de intervir sobre o território. Ramos (2006) indicou que as limitações da maioria dos estados em gerirem por si a imigração demandaram a intervenção federal, abrindo caminho para a expansão da autoridade nacional pelo território através 
do Serviço de Povoamento do Solo Nacional. Sobre a institucionalização da reforma sanitária ver Castro Santos (2004: $156,261)$.

3. Alguns exemplos podem ser dados, como Rosenberg (1992), Cooper (1986), Evans (1988) e Briggs (1961).

4. No século XIX, as doenças eram divididas em infecciosas, ligadas a miasmas e às condições climáticas (a malária fazia parte deste grupo), e contagiosas, transmitidas por contato direto com o doente, ou pelos objetos contaminados por suas secreções (varíola). A contagiosidade da cólera foi aceita em 1866, durante a $3^{\text {a }}$ Conferência Sanitária Internacional, realizada em Constantinopla. A descoberta de suas vias de transmissão - descritas por Robert Koch, em 1888, no Egito - não modificou significativamente as práticas de prevenção nos portos, que continuaram sendo $\mathrm{o}$ isolamento a e desinfecção dos passageiros (Löwy, 2006: 30-35).

5. Arquivo Nacional - AN. Série Justiça, notação IJ1-1026 - Consulado e Vice-Consulado do Brasil em Barcelona 1892-1897avisos sobre portos infeccionados pela cólera.

6. Brasil, Relatório do Ministério da Justiça e Negócios Interiores [RMJNI] - Relatório da Inspetoria Geral de Saúde dos Portos, 1893/1894:274; Relatório do Ministério da Indústria, Viação e Obras Públicas [RMIVOP], 1896: 69; RMJNI, 1892/1893: 337; 1893/1894: 277.

7. Livre prática é a autorização emitida pela polícia sanitária para uma embarcação entrar no porto e realizar as operações de desembarque de cargas e passageiros (RMJNI: 1894-1895).

8. Para a legislação brasileira, o que caracterizava um passageiro como imigrante era a sua vinda com passagens de $2^{\mathrm{a}}$ ou $3^{\mathrm{a}}$ classe pagas pelo governo (RMIVOP, 1908,
Bases Regulamentares do Serviço de Povoamento, art. 42:114).

9. Dez dias para a cólera, oito para a febre amarela e vinte para a peste bubônica (Santos, 2009: 1.173-1.196).

10. As estufas de desinfecção eram geralmente da marca alemã Genester-Herscher. Elas funcionavam através do vapor d'água sob pressão, possuíam duas portas, uma para o lado impuro, onde recebia a roupas infectadas, e outra para o lado puro, onde as roupas eram devolvidas, após o processo de desinfecção (Silvado, 1903).

11. Ver, entre outros, Fornal do Commercio, 29 de agosto de 1893, p.1; Gazeta de Notícias, 27 de agosto- 2 de setembro de 1893, p.1.

12. Do porto para a cidade e desta para o interior, era esta, justamente, a marcha das epidemias de febre amarela, cólera e a peste, que frequentemente se faziam presentes no país (Lamarão, 1991: 55).

13. Durante a $9^{\text {a }}$ Conferência Sanitária Internacional, em 1894, o governo italiano teve a oportunidade de relembrar o ocorrido no ano anterior: os passageiros dos quatro navios haviam passado por uma completa inspeção médica nos portos de embarque, deixando Nápoles em perfeitas condições de saúde. No entanto, foram recusados como imigrantes no Brasil. Um dos vapores, o "Carlo R", retornou à Itália com 522 mortos. A delegação italiana utilizou o episódio para fazer oposição às propostas dos EUA, que tentavam, sem sucesso, convencer os representantes das outras nações sobre a importância do controle sanitário de emigrantes europeus para as Américas (Howard-Jones, 1975: 73).

14. Um aspecto das epidemias é a impossibilidade de realização dos ritos tradicionais relacionadas à morte como a toalete fúnebre, o velório e o enterro. Destituída desta liturgia, a morte é dessacralizada e se 
torna ainda mais temível (Delumeau, 2009: 154-170).

15. Durante o Império, as políticas de saúde ocorreram em dois momentos e de forma antagônica. Num primeiro ato, as organizações centralizadoras, criadas por D. João VI, caminharam para uma municipalização de todas as atividades sanitárias. Depois, num movimento contrário, em meados do século XIX, voltou-se à uniformização administrativa dos trabalhos de higiene pública, colocados inteiramente nas mãos do governo central. Esse movimento na direção de uma centralização administrativa ocorreu por causa da necessidade de se combater as epidemias nas zonas litorâneas, nas zonas de expansão econômica e de imigração (Hochman, 1998; Telarolli Junior, 1996).

16. Harrison (2006) mostrou que no início do século XIX, nações europeias começaram a contemplar formas de cooperação em assuntos sanitários, principalmente relacionados aos portos, dando início a um processo diplomático que culminou nas conferências sanitárias internacionais e nas primeiras leis para o controle de doenças infecciosas. Sobre as convenções sanitárias americanas, ver Cueto (2007) e Howard-Jones (1981). A respeito das conferências européias existem os estudos de Bynum (1993), Howard-Jones (1975) e Mateo (2005).

17. Para uma descrição detalhada da construção do lazareto, assim como de suas instalações, ver Santos (2009).

18. Sobre a febre amarela e a microbiologia no Brasil, ver Benchimol (1999). Chalhoube (1995) faz uma abordagem desta doença, correlacionando-a às questões raciais no século XIX. Sobre o pensamento higienista, ver Maio (2004).

19. A microbiologia era a teoria do cientista francês Louis Pasteur (1873), segun- do a qual as doenças eram transmitidas por seres "infinitamente pequenos", convencionalmente chamados de micróbios.

20. Ackerknecht (1948) demonstrou a existência de uma correlação entre o sistema político e a saúde pública. Em seu argumento, a escolha por determinada forma de prevenção não era ditada pela natureza da doença, mas pelo regime político. Assim, uma ideologia autocrática favorecia a visão das doenças epidêmicas como contagiosas e, consequentemente, aplicava a quarentena. Regimes liberais, em contraste, possuíam uma visão infeccionista e preferiam corrigir as deficiências do meio como uma forma de prevenção. Para uma crítica a esta visão, ver Baldwin (1999).

21. Essas e as demais informações sobre os procedimentos adotados pelas autoridades brasileiras em relação às ameaças representadas pelas doenças foram retiradas de AN. Série Saúde, notação IS3-35 (18581895) - Organização Sanitária Marítima do Brasil, manuscrito de 12 de abril de 1890.

22. O Brazil-Médico, 1896, ano X, p. 24. Essa mesma fonte informa que os lazaretos e os hospitais flutuantes eram uma espécie de barca improvisada com enfermaria. As enfermarias flutuantes poderiam ser utilizadas também para realizar o transporte dos enfermos do navio para o lazareto.

23. Os desinfetantes utilizados nos processos de desinfecção eram o enxofre, para os passageiros, e o cloreto de zinco e o ácido fênico, para as bagagens. Roupas e objetos eram desinfectados pelo vapor quente sob pressão, aplicado pelo tipo de estufa ou pulverizador (AN. Série Saúde, notação IS3-35 (1858-1895) - Organização Sanitária Marítima do Brasil, manuscrito de 12 de abril de 1890). 
ACKERKNECHT, H. Anticontagionism between 1821-1867. Bulletin of History of Medicine, n.22, 1948, p. 562-593.

BALDWIN, Paul. Contagion and the State in Europe 1830-1930. Nova York: Cambridge University Press, 1999.

BENCHIMOL, Jaime L.. Dos micróbios aos mosquitos: febre amarela e a revolução pasteuriana no Brasil. Rio de Janeiro: Fiocruz, 1999.

BIRN, Anne-Emanuelle. Six seconds per eyelid: the medical inspection of immigrants at Ellis Island, 1892-1914. DYNAMIS. Acta Hisoanica ad Medicinae Scientiarumque Historiam Illustrandam, vol.17, 1997, p. 281-316.

BRIGGS, Asa. Cholera and society in the nineteenth century. Past and Present, n. 19, 1961, p. 76-96.

BYNUM, W.F.. Policing Hearts of Darkness: aspects of the international sanitary conference. Hist. Phil. Life Sci., 15, 1993, p. 421-434

CAPONI, Sandra. Trópicos, microbios y vectores. História, Ciências, Saúde - Manguinhos, vol. 9 (suplemento), 2002, p. 111138.

CASTRO SANTOS, Luiz Antonio de. Poder, ideologia e saúde no Brasil da Primeira Repúbica: ensaio de sociologia histórica. In: ARMUS, Diego \& HOCHMAN, Gilberto (org). Cuidar, controlar, curar: ensaios históricos sobre a saúde e doença na América Latina e Caribe. Rio de Janeiro: Ed. Fiocruz, 2004, p. 249-293.

CHALHOUB, Sidney. Febre amarela e ideologia racial no Rio de Janeiro do século XIX. Estudos Afro-Asiáticos, 27, 1995, p. 87-110.
COOPER, Donald B. The new "black death": cholera in Brazil, 1855-1856. Social Science History, v.10, n.4, 1986, p. 467-488.

COSTA LEITE, Joaquim da. O Brasil e a emigração portuguesa (1855-1914). In: FAUSTO, Boris et al. Fazer a América: $a$ imigração em massa para a América Latina. São Paulo: EDUSP, 2000, p. 177-200.

CUETO, Marcos. O valor da saúde: história da Organização Pan-Americana da Saúde. Tradução Vera Ribeiro. Rio de Janeiro: Editora Fiocruz, 2007.

DELUMEAU, Jean, 1923. História do medo no ocidente 1300-1800: uma cidade sitiada. Tradução de Maria Lúcia Machado; tradução de notas de Heloísa Jahn. São Paulo: Companhia das Letras, 2009.

EVANS, Richard J. Epidemics and revolution: cholera in nineteenth century Europe. Past and Present, $\mathrm{n}^{\circ} 120$, ago. 1988, p. 123-146.

FAIRCHILD, Amy L. The rise fall of the medical gaze: the political economy of immigrant medical inspection in the Modern America. Science in Context, vol. 19, n.3, 2006, p. 337-356.

HARRISON, Mark. Disease, Diplomacy and International Commerce: The origins of international sanitary regulation in the nineteenth century. Fournal of Global History, vol.1, n. 2, julho de 2006, p. 197-217.

HOCHMAN, Gilberto. A era do saneamento: as bases políticas da saúde pública no Brasil. São Paulo: Hucitec/ANPOCS, 1998.

HOWARD-JONES, Norma. The Scientific Background of International Sanitary Conference, 1851-1938. Genebra: World Health Organization, 1975. 
The Pan American Health Organization, Origins and Evolution. Genebra: World Health Organization, 1981.

KLEIN, S. Herbert. Migrações internacionais na história das Américas. In: FAUSTO, Boris. Fazer a América: a imigração em massa para a América Latina. São Paulo: Edusp, 2000, p. 13-31.

KRAUT, Alan. Silent Travelers, Germs, Genes and the "Immigrant Menace". Baltimore: The Johns Hopkins University Press, 1994.

LAMARÃO, Sérgio. Dos trapiches ao porto: um estudo sobre a área portuária do Rio de Faneiro. Rio de Janeiro: Secretaria Municipal de Turismo e Esportes, 1991.

LEWINSOHN, Rachel. Três epidemias do passado. São Paulo: Editora Unicamp, 2003.

MAGLEN, Krista. "The First Line of Defense": British Quarantine and the Port Sanitary Authorities in the Nineteenth Century. The Social History of Medicine, vol.15, n.3. 2002, p. 413-428.

MAIO, Marcos Chor. Raça, doença e saúde pública no Brasil: um debate sobre o pensamento higienista do século XIX. In: MONTEIRO, Simone \& SANSONE, Livio (orgs.). Etnicidade na América Latina: um debate sobre raça, saúde e direitos reprodutivos. Rio de Janeiro: Editora FIOCRUZ, 2004, p. 15-44.

MASSOW, Hilário. Estudo do Rio de Faneiro: composto sobre os últimos mapas. Rio de Janeiro: Laemmert, 1892.

MATEO, Jiménez Juan B. Actas de las conferencias sanitarias internacionales (18511938). Revista Española de Salud Pública, vol. 79, n³-maio-junho 2005, p. 339-349.
RAMOS, Jair de Souza. O poder de domar o fraco: construção de autoridade e poder tutelar na política de povoamento do solo nacional. Niterói: Editora da UFF, 2006.

ROSENBERG, Charles E. Explaining Epidemics and Other Studies in the History of $\mathrm{Me}$ dicine. Cambridge: Cambridge University Press, 1992 (cap. 14 - Explaining Epidemics, p. 293-304).

SANTOS, Myrian Sepúlveda dos. Os porões da República: a barbárie nas prisões da Ilha Grande, 1894-1945. Rio de Janeiro: Garamond, 2009.

SARDINHA, Joaquim J. da S. Hygiene Pública: apontamentos para a história da $R e$ partição de Saúde do Porto do Rio de Faneiro offerecidos ao Instituto Histórico Geográfico Brasileiro. Rio de Janeiro: Imprensa Nacional, 1916.

SILVADO, Jaime. A febre amarela a bordo do Lombardia: notas críticas para servirem à história da epidemia. Revista Médica de São Paulo - Fornal Prático de Medicina, Cirurgia e Hygiene, anno VI, n. 15, 15 de agosto de 1903.

SODRÉ, Azevedo. A epidemia de cholera-morbus de 1894-1895. O Brazil-Médico, ano IX, n. 26, 8 de julho de 1895, p. 226.

TELAROLLI JUNIOR, Rodolpho. Poder e saúde: as epidemias e a formação dos serviços de saúde em São Paulo. São Paulo: Editora da Universidade Estadual Paulista, 1996.

WEINDLING, Paul (org.). International Health Organization and Movements 19181939. Cambridge: Cambridge University Press, 1995. 


\section{Resumo}

Este artigo aborda as relações entre saúde pública, imigração e epidemias, tendo como foco os navios de imigrantes acometidos pela cólera, que chegaram ao porto do Rio de Janeiro entre o final do século XIX e início do XX. A análise é organizada a partir de quatro navios de imigrantes, que deveriam ter permanecido em quarentena, mas foram obrigados a retornar viagem aos portos de origem por apresentarem cólera a bordo. São analisados os esforços dos serviços sanitários para impedir o ingresso de doenças no país e, ao mesmo tempo, garantir o fluxo de mercadorias e de mão de obra imigrante.

Palavras-chaves: imigração; epidemias; porto; saúde pública; Rio de Janeiro; cólera.

\section{Abstract}

This article examines the relationship among public health, immigration, and epidemics, focusing on the immigrant ships affected by cholera, which arrived at the port of Rio de Janeiro in the late nineteenth and early twentieth centuries. The analysis is based on four immigrant ships, which should have remained in quarantine, but were forced to return trip to the ports of origin, due to the fact that they had cases of cholera on board. The article analyzes the efforts of health services to prevent ingress of diseases in the country and, at the same time, ensure the flow of goods and immigrant labor.

Keywords: immigration; epidemics; port; public health; Rio de Janeiro; cholera.

\section{Résumé}

Cet article traite de la relation entre la santé publique, l'immigration et les épidémies, en se concentrant sur les bateaux d'immigrants touchées par le choléra, qui sont arrivés au port du Rio de Janeiro à la fin du XIXème et au début du XXème siècles. L'analyse est organisée à partir de quatre bateaux d'immigrants, qui auraient dû rester en quarantaine, mais ils ont dû aller-retour vers les ports d'origine parce qu'ils avaient le choléra à bord. Les efforts des services de santé pour prévenir la pénétration des maladies dans le pays et, en même temps, assurer la circulation de marchandises et de main-d'oeuvre immigrante sont aussi analysés.

Mots-clés: immigration; épidémies; port; santé publique; Rio de Janeiro; choléra. 